Ruth Endacott

Christina Jones

Melissa J. Bloomer

Carole Boulanger

Maureen Ben Nun

Katerina K. lliopoulou

Ingrid Egerod

Stijn Blot

\section{The state of critical care nursing education in Europe: an international survey}

Accepted: 12 September 2015

Published online: 1 October 2015

(C) The Author(s) 2015. This article is published with open access at

Springerlink.com

Dear Editor,

Critical care nursing $(\mathrm{CCN})$ is an increasingly complex and growing area of specialty practice [1]. Yet access to specialty training and high quality $\mathrm{CCN}$ education remains a significant issue for $\mathrm{CCN}$ [1], creating role confusion between countries for $\mathrm{CCN}$, impeding mobility across Europe and career progression for the $\mathrm{CCN}$ workforce [2].

To overcome similar problems in intensive care medicine (ICM), the
CoBaTrICE programme was developed. A competency-based training programme for ICM across Europe $[3,4]$, this programme has been adopted in 15 European countries and provides a common set of programme standards and ensures ICM is recognised as a primary specialty area for physicians [4].

The purposes of this study were to (i) map adult $\mathrm{CCN}$ education programmes; (ii) examine existing educational structures, processes and outcomes; and (iii) identify the barriers to advancing $\mathrm{CCN}$ education programmes across Europe, through the use of a descriptive survey of registered nurses in leadership roles within $\mathrm{CCN}$ organisations. The survey was completed via telephone, online and in hard copy in order to optimise recruitment.

Twenty-four European countries were represented, and challenges or problems for teaching or training $\mathrm{CCN}$ were identified in 22 of these. Formal $\mathrm{CCN}$ education programmes were provided in 17 (70 \%) of countries (Table 1) and $\mathrm{CCN}$ was recognised as a specialty in 13 $(54.2 \%)$ of countries. Where education programmes were provided, eligibility requirements and programme duration varied considerably, ranging from $240 \mathrm{~h}$ to 24 months, with no consistency in how students were assessed/examined, or qualification awarded. The lack of national standard for teaching and training nurses in intensive care was also a problem identified in $12(54.5 \%)$ countries, followed by a lack of time for trainers to devote to teaching in 14 $(63.6 \%)$ countries, a lack of protection for the title in $10(45.5 \%)$ countries, limited work hours/shift work impacting teaching and training in the ICU in $9(40.9 \%)$ countries and a lack of access to educational resources in $6(27.3 \%)$ countries.

Our results indicate that the first challenge is the recognition of $\mathrm{CCN}$ as a specialty area across Europe. The second challenge is the development of a Europe-wide specialist education programme that results in nurses with the knowledge, skills and expertise fit-for-purpose for the increasing patient acuity in critical care [5]. The third challenge is to ensure changes to the nursing workforce across Europe, such as implementing a framework that enables advanced practice roles in $\mathrm{CCN}$ to be recognised and regulated, and enable suitably qualified critical care nurses to work freely across country borders.

In conclusion, there are significant barriers impeding the development and advancement of $\mathrm{CCN}$ education across Europe. A Europe-wide approach to addressing these is 
2238

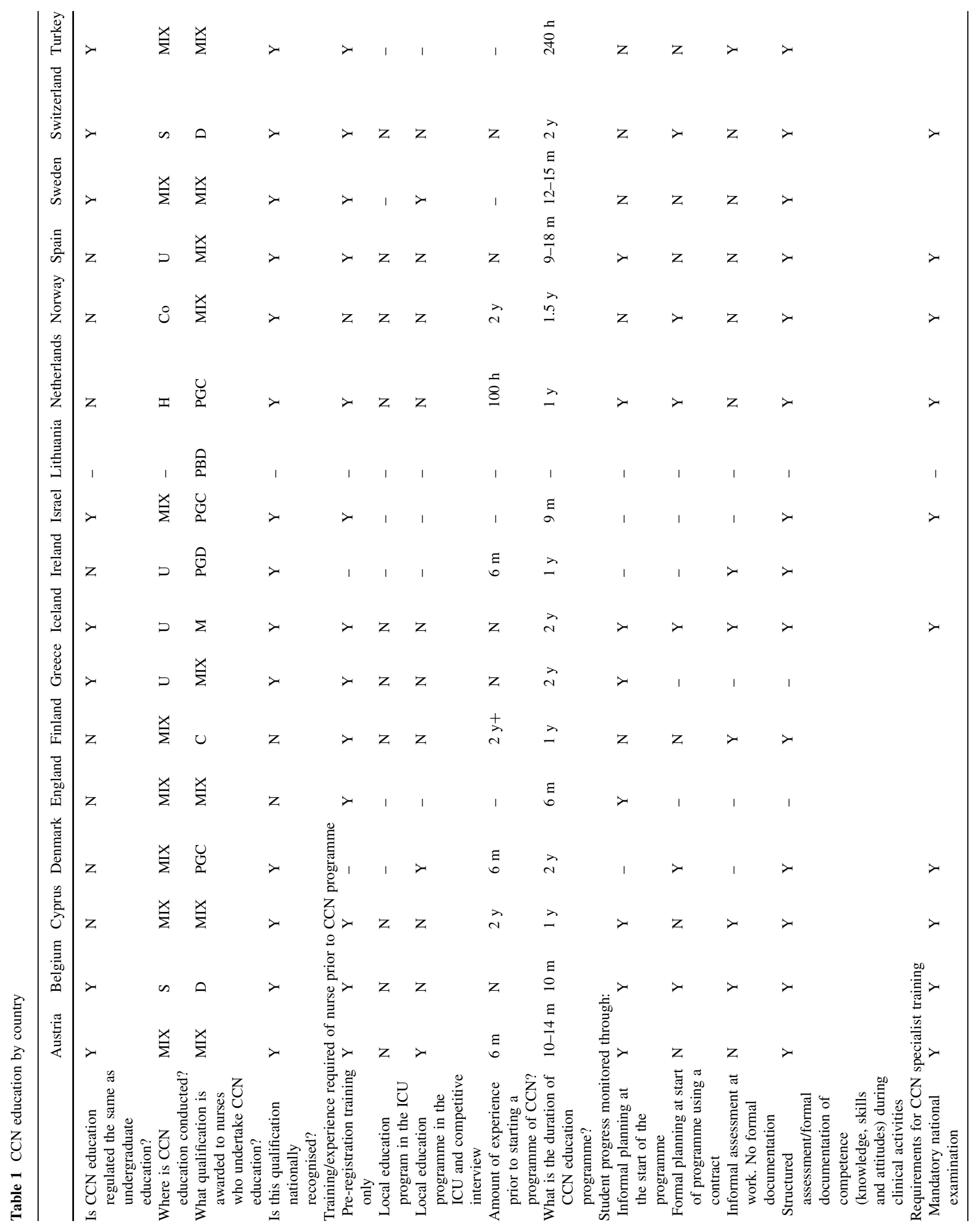




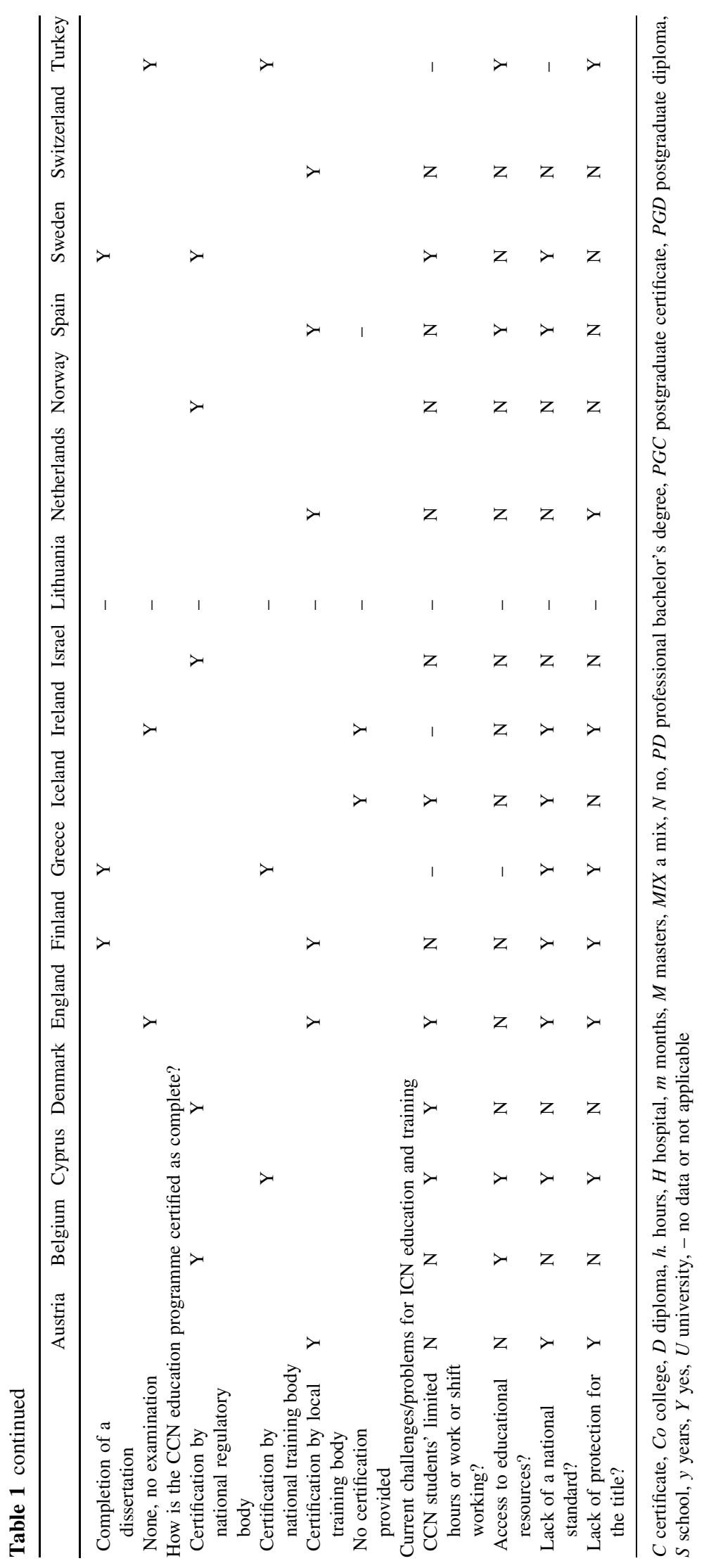


imperative before $\mathrm{CCN}$ can advance as an area of specialty practice and meet the increasing needs of the critically ill patient.

\section{Compliance with ethical standards}

Conflicts of interest None of the authors have conflicts of interest.

Open Access This article is distributed under the terms of the Creative Commons Attribution-NonCommercial 4.0 International License (http://creativecommons.org/ licenses/by-nc/4.0/), which permits any noncommercial use, distribution, and reproduction in any medium, provided you give appropriate credit to the original author(s) and the source, provide a link to the Creative Commons license, and indicate if changes were made.

\section{References}

1. Williams G et al (2011) Critical care nursing organizations and activities: a third worldwide review. Int Nurs Rev 59:73-80. doi:

10.1111/j.1466-7657.2011.00926.x
2. Dury C et al (2014) Specialist nurse in Europe: education, regulation and role. Int Nurs Rev 61:454-462. doi: 10.1111/inr.12123

3. Barrett H, Bion J (2005) An international survey of training in adult intensive care medicine. Int Care Med 31:553-561. doi: 10.1007/s00134-005-2583-7

4. Bion J, Rothen H (2014) Models for intensive care training: a European perspective. Am J Resp Crit Care Med 189:256-262. doi: 10.1164/rccm.201311-2058CP

5. Labeau S, Chiche J-D, Blot S (2012) Post-registration ICU nurses education: plea for a European curriculum. Int $\mathbf{J}$ Nurs Stud 49:127-128. doi: 10.1016/j.ijnurstu.2011.07.014

R. Endacott · M. J. Bloomer (®) School of Nursing and Midwifery, Monash University, Frankston, VIC, Australia e-mail: melissa.bloomer@monash.edu

R. Endacott

Plymouth University, Plymouth, UK

C. Jones

Institute of Aging and Chronic Disease, Department of Musculoskeletal Biology, University of Liverpool, Liverpool, UK
C. Boulanger

Royal Devon \& Exeter NHS Foundation

Trust, Exeter, UK

M. Ben Nun

Kaplan Medical Center, Yavné, Israel

K. K. lliopoulou

Florence Nightingale Faculty of Nursing and Midwifery, King's College London, London, UK

I. Egerod

Trauma Centre, Rigshospitalet, University of Copenhagen, Copenhagen, Denmark

S. Blot

Department of Internal Medicine, Ghent University, Ghent, Belgium

S. Blot

Burns, Trauma and Critical Care Research Centre, The University of Queensland, Brisbane, Australia 